\title{
A POLÍTICA NACIONAL DE AVALIAÇÃO DO ENEM: A PROPOSTA DE REDAÇÃO E O IMAGINÁRIO DE ESCRITOR IDEAL
}

\section{THE NATIONAL ENEM EVALUATION POLICY: THE EDITORIAL PROPOSAL AND THE IDEAL WRITER IMAGINARY}

\author{
Amilton Flávio Coleta Leal ${ }^{1}$ \\ Ana Luiza Artiaga Rodrigues da Motta ${ }^{2}$ \\ Universidade do Estado de Mato Grosso
}

\section{RESUMO}

Este trabalho, inscrito na perspectiva da Análise de Discurso Materialista de Linha Francesa, com Michel Pêcheux, e Eni Orlandi, no Brasil, tem por objetivo refletir sobre a política de avaliação do Exame Nacional do Ensino Médio (ENEM), a partir da formulação da proposta de redação, enquanto um repetível que aponta para um imaginário de leitor/escritor "ideal", projetado pelo discurso do Exame. Dessa maneira, as reflexões aqui articuladas dizem respeito à maneira como um sistema de avaliação em larga escala, em seu efeito classificatório, aponta para um imaginário de língua (escrita) e, consequentemente, para um perfil de aluno que se "enquadre" às normas ditas pelo Estado. Para tanto, destacamos a relevância deste estudo para o domínio da linguagem, sobretudo, para os pesquisadores que se voltam a pensar sobre as políticas educacionais, pois, dada a importância desse Programa para o Estado, observa-se que as análises refletem a constituição do sujeito institucionalizado por um imaginário de escrita, o que possibilita refletirmos, ainda, a projeção imaginária da posição-sujeito-aluno "ideal" para a escrita da redação. Estas questões nos possibilitam dizer que o modo como o sujeito se relaciona com escrita tem a ver com o modo como ele se relaciona com o conhecimento, com a linguagem e com a sociedade.

PALAVRAS-CHAVE: Discurso; ENEM; Escrita; Imaginário; Posição-sujeito.

\begin{abstract}
This work, inscribed in the perspective of the French Line Materialist Discourse Analysis with Michel Pêcheux and Eni Orlandi in Brazil, aims to reflect on the evaluation policy of the National High School Examination (ENEM), from Formulation of the writing proposal, while a repeatable one that points to an "ideal" reader / writer's imagination, projected by the discourse of the Exam. Thus, the reflections articulated here relate to the way in which a large-scale evaluation system, in its classificatory effect, points to an imaginary language (written) and, consequently, to a student profile that "conforms" to the norms Dictated by the State. Therefore, we highlight the relevance of this study to the domain of language, especially for researchers who are thinking about educational policies, because, given the importance of this Program for the State, it is observed that the analyzes reflect the constitution of the Subject institutionalized by an imaginary of writing, which makes it possible to reflect, also, the imaginary projection of the

1 Mestre e doutorando em Linguística pela Universidade do Estado de Mato Grosso (UNEMAT). E-mail: amiltonflavio@hotmail.com

${ }^{2}$ Doutora em Linguística pela Universidade Estadual de Campinas (UNICAMP). E-mail: analuizart@,unemat.br
\end{abstract}


"ideal" subject-student position for the writing of the essay. These questions enable us to say that how the subject relates to writing has to do with how it relates to knowledge, language, and society.

KEY WORDS: Discourse; ENEM; Writing; Imaginary; Subject-position.

\section{INTRODUÇÃO}

O que move a teoria é o próprio objeto e esse nos coloca em lugares teóricos diferentes. Orlandi (2003) ${ }^{3}$ dirá que é porque o analista tem um objeto a ser analisado que a teoria vai se impondo. Diante disso, trazemos para a trama pensar o ENEM (Exame Nacional do Ensino Médio) enquanto fato discursivo de linguagem, que recorta questões sobre os gestos de leitura e de escrita enquanto práticas que permeiam as distintas condições de produção dos sujeitos e das instituições nas quais estes estão inscritos.

A nosso ver, refletir sobre a política nacional de avaliação do ENEM faz emergir questões muito 'caras' ao ensino no Brasil, dentre estas, uma questão que se impõe para os que trabalham com a Análise de Discurso é a da relação dos processos de ensino aprendizagem, particularmente, a relação sujeito/escrita. Essa é uma questão que nos instiga, pois o Exame Nacional é uma avaliação em larga escala que está posta, atualmente, como condição de acesso ao ensino superior para a grande maioria das universidades no país. São essas e outras questões que nos movem a refletir as discursividades do Exame Nacional e seus efeitos de sentido produzidos em âmbito nacional.

O processo avaliativo do ENEM é uma prova que, ao longo de suas sucessivas edições (1998-2016) tem provocado inúmeros questionamentos em relação à política avaliativa que a sustenta. De sua instituição até a presente edição (2016), várias críticas foram tecidas sobre a maneira como o Exame avalia o candidato. Diante disso, várias reformulações foram feitas e essas constantes re(adequações) pelas quais o ENEM passou nos dão pistas do quão instável é a política avaliativa de um Exame que se propõe avaliar em larga escala.

Ao apontarmos, ainda que rapidamente, questões que tocam "negativamente" o Exame Nacional, nossa reflexão, nesta escrita, não incidirá sobre tais críticas, mas recairá sobre nossa inquietação em relação à política avaliativa do Exame, mais especificamente, o repetível inscrito na formulação da proposta de redação.

Ao dizermos que o ENEM, a cada edição, vem conquistando maior espaço nas políticas de avaliação do país podemos pensar que essa repercussão e legitimidade da prova ocorreram ao longo de suas sucessivas edições e isso fez com que, atualmente, ele ocupasse a centralidade das discussões no cenário educacional, seja do ensino médio e/ou da educação superior.

Posto isso, nossa escolha em estudar as discursividades das políticas de língua, a partir do ENEM, se deve a um conjunto de fatores, dentre estes, o de refletir os efeitos de sentido produzidos por um imaginário de aluno e de escrita "ideais" projetado no processo avaliativo, em particular, na maneira como está posta a formulação da proposta de redação do Exame. Dessa forma, dada a relevância desse Programa Avaliativo para a nação, propomos pelas análises, refletir sobre a política nacional de língua escrita inscrita nas proposições do Exame Nacional, em que abre-se espaço para pensarmos a constitutividade do sujeito institucionalizado pelas normas de escrita do Estado.

Ao tomarmos o ENEM como objeto de análise, estamos lidando com um fato de linguagem que nos dá pistas da "severa" disputa para o acesso ao Ensino Superior, pois esse processo avaliativo provoca efeitos de sentido nas discussões sobre a qualidade do ensino no país, sobretudo, no que diz respeito à maneira como são selecionados os candidatos para o acesso às Universidades no país, o que produz gestos de interpretação que repercutem na maneira como está "posta" a distribuição de vagas nas Instituições de Ensino Superior (IES), sejam elas públicas

3 Prefácio da obra “A Inquietação do Discurso" (Maldidier, 2003). 
e/ou privadas. Dessa forma, considerando-se que o Exame Nacional trata-se de uma avaliação em larga escala, em que há uma instabilidade em relação à sua política avaliativa, a nosso ver precisa-se de um olhar atento para as condições de produção dos sujeitos-participantes, o que produz, como efeito da avaliação, a aprovação de uns e a exclusão de muitos. Essa questão da "exclusão" é algo que apenas levantamos aqui, mas precisa ser trabalhada minuciosamente/analiticamente, uma vez que se abre para questões maiores no campo da democratização, enquanto políticas de acesso, permanência, etc.

Posto isso, nos perguntamos: por que pensar a política de escrita do Exame Nacional? Para nós, enquanto fato discursivo de linguagem, este processo avaliativo/seletivo recorta questões sobre os gestos de leitura, de escrita e de interpretação e de condições de produção dos sujeitos. Isso nos possibilita refletir, de maneira particular, a questão da leitura, da escrita e da interpretação, enquanto práticas que nos fazem olhar para o vão das versões ${ }^{4}$ e seus efeitos de sentido. Questões que nos movem a pensar, enquanto pesquisadores da linguagem, que o discurso é o lugar da incompletude, do movimento. Serão estes dispositivos teórico-analíticos que nos servirão de fundamento às análises, posteriormente.

A nosso ver, inscrevermos na teoria da Análise de Discurso, enquanto vertente teórica, significa compreendermos um fato de linguagem em movimento (batimento entre descrição e interpretação), pensando os fatos sociais, políticos e linguísticos, de maneira particular. A referida teoria nos permite refletir sobre questões aparentemente 'naturalizadas'; isso porque cabe ao analista de discurso trabalhar nos limites da interpretação, indagando a literalidade dos sentidos e os efeitos da interpretação com um "outro olhar" sobre o objeto simbólico. Ou seja, nossa questão fulcral é desnudar a evidência posta, refletindo sobre os sentidos outros diante do que o objeto simbólico nos oferece enquanto materialidade simbólica significante.

Dito de outro modo, este é um gesto em que o trabalho com "a linguagem não se dá como evidência, mas oferece-se como lugar de descoberta, lugar do discurso" (ORLANDI, 2009, p. 96). É, portanto, nesse espaço do "possível", que trabalharemos a Análise do Discurso como perspectiva teórica e ancoragem analítica no processo de análise do corpus. Para tanto, será o dispositivo teórico-analítico ${ }^{5}$ - batimento entre descrição e interpretação - que sustentará a nossa reflexão no que concerne à materialidade discursiva sobre a Política Nacional de Avaliação do ENEM.

\section{A política nacional de avaliação do ENEM: o acesso ao ensino superior}

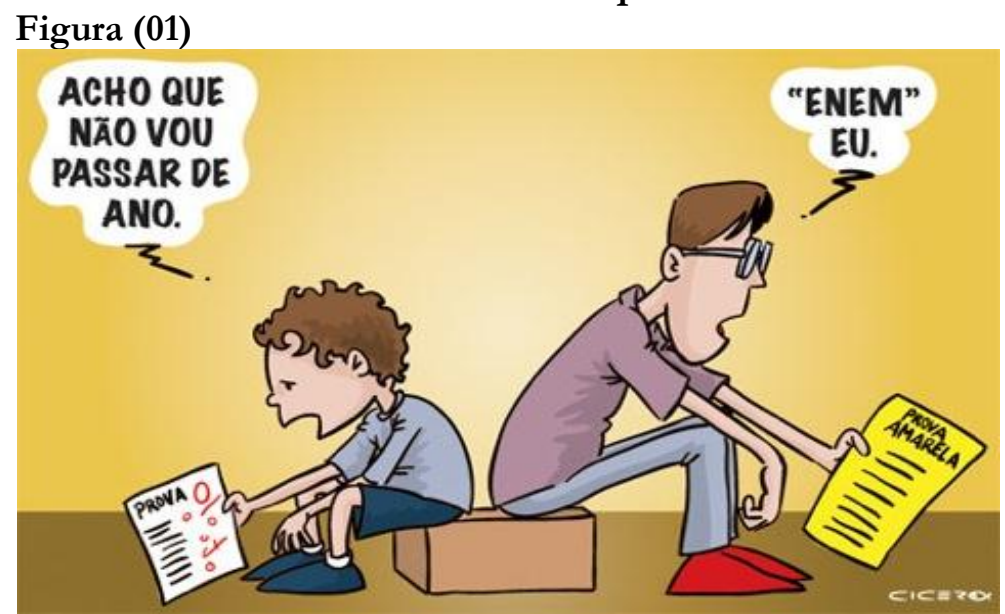

Fonte: Google Imagens/Charges do ENEM ${ }^{6}$

\footnotetext{
${ }^{4}$ Referimo-nos à Orlandi (2012), que diz na epígrafe de seu livro "Discurso e Texto": o que há são versões.

${ }^{5} \mathrm{~A}$ análise se dá a partir do batimento entre o dispositivo teórico e analítico, sendo este último configurado pela relação entre material de análise e teoria (ORLANDI, 2001).

${ }^{6}$ A charge em leitura recorta uma questão de ensino, sobre a qual nos deteremos nas análises, a posteriori.
} 
Grosso modo, o ENEM é uma prova que deriva de uma política do INEP $^{7}$ (Instituto Nacional de Pesquisa e Estatística Anísio Teixeira), legitimada por um discurso pedagógico que diz sobre o processo avaliativo do aluno ao final do ensino médio, o qual passou a funcionar, ao longo das edições, como uma política avaliativa que possibilita o acesso ao ensino superior. Diante disso, ao tomarmos a política nacional de avaliação do Exame Nacional, nos inscrevemos em um lugar teórico-analítico para refletirmos sobre uma questão muito 'cara' ao ensino no Brasil: a relação dos processos de ensino e aprendizagem via ENEM.

$\mathrm{Na}$ esteira do que estamos dizendo e para fazermos alusão ao exposto, trazemos a imagem da figura (01) como um gesto de leitura que nos faz pensar as políticas de ensino, particularmente, as avaliações em larga escala e com elas a disputa de acesso ao Ensino Superior. Discursivamente, a imagem e a formulação (fig.01, "acho que não vou passar de ano; ENEM eu") produz um lugar de leitura que remete ao ensino e aprendizagem, ao processo avaliativo do ENEM. A relação da referida imagem com as questões que dizem respeito a esse processo de aprendizagem produz como efeito uma linha tênue e nos permite dizer que há, no espaço das políticas de escrita, um lugar de divisão, de bifurcação entre os que têm e os que não têm acesso a esses lugares legitimados.

A charge da figura (01) aponta para o ENEM e para o acesso à Universidade, com uma linguagem humorística, em que a personagem $\mathrm{P}^{1}$ diz: "acho que não vou passar de ano" e, $\mathrm{P}^{2}$ responde: "ENEM" eu. Temos, na materialidade simbólico-discursiva, um efeito metafórico, tal como formulou Pêcheux (1969), uma deriva, um deslizamento de sentido. Observa-se que há uma mobilidade de sentidos no uso da palavra ENEM, em que o efeito metafórico da justaposição (e nem) desliza para sentidos outros de reprovação e de negação no processo seletivo do Exame Nacional, ou seja, na linguagem cotidiana de se dizer "e nem eu" tem-se o efeito de exclusão, de decréscimo em não obter uma boa nota, o que significa, ao fio do discurso, 'estar fora' do ensino superior.

Pensar o processo avaliativo do ENEM nos conduz a refletir sobre o Estado-Avaliador (ALVES, 2009), como lugar em que as políticas educacionais assumem estratégias na busca pela melhoria e eficiência na qualidade da educação. Ao falar de Estado-Avaliador, Alves (2009) traz Sobrinho (2003, p.59) para dizer que, como avaliador ou interventor, o Estado costuma praticar uma avaliação predominantemente controladora e organizadora de suas políticas de distribuição de recursos. Em geral, são avaliações externas, somativas, orientadas para o exame dos resultados, e seguem prioritariamente os paradigmas objetivistas e quantitativistas.

Nessa direção, compreendemos que o 'Estado-Avaliador' assume funções prioritárias de legislar e avaliar, pois ao organizar e realizar o ENEM, textualiza-se, também, o processo educacional a partir das políticas públicas que, por sua vez, fixam e definem os processos de avaliação, dando visibilidade às questões referentes ao ensino no país, a partir dos resultados desses processos. Isso posto, nos permite entender que o Estado avaliador intervém no controle e na organização de um exame que objetiva resultados numéricos, que midiatiza e estratifica o nível de ensino-aprendizado do país. Expliquemos essa questão:

O filtro/resultado produzido pelo INEP, a partir da avaliação do ENEM, funciona como um seletivo que institui o acesso à Universidade. Isso faz com que o Exame, ao longo das edições, deixe de ser, eminentemente avaliativo, e passe a funcionar como possibilidade de ingresso ao ensino superior. Esta é uma questão que retoma a charge, em análise, que diz entre outras coisas, sobre um fio condutor que aponta para a relação ensino fundamental $\rightarrow$ ensino médio $\rightarrow$ ENEM $\rightarrow$ ensino superior. Esta é uma relação constitutiva, entretanto, é naturalizada pelo efeito de evidência, ou seja, dizer desses processos faz, muitas vezes,

\footnotetext{
7 O INEP é um órgão ligado ao próprio MEC. Surgiu em 1984 e funciona como um sistema de informações, pesquisas e estatísticas na publicação dos resultados de avaliação de todas as etapas de ensino. Disponível em www.inep.gov.br. Acessado em: 16 de nov. de 2016.
} 
escamotear as condições de produção do sujeito-aluno e da instituição em que este está inscrito. E o Exame, enquanto avaliação unificada corrobora para que essa discrepância seja materializada nos gráficos numéricos que dizem sobre o ensino no Brasil. Nessa linhagem, compreendemos que a política nacional do Exame Nacional configura um apontamento para o ensino fundamental e médio, uma vez que o acesso ao ensino superior depende da base constitutiva destas etapas de ensino.

\section{A formulação da proposta de redação do ENEM: um repetível que produz sentido(s)}

A prova discursiva do Exame Nacional avalia as competências do candidato em relação à sua capacidade de produzir um texto dissertativo-argumentativo, seu posicionamento crítico da realidade, e que respeite a diversidade sociocultural e os valores humanos. Para isso, são disponibilizados, junto à proposta de redação, os textos motivadores ${ }^{8}$, que funcionam como mecanismos de suporte para a escrita; uma maneira de o participante refletir sobre a temática da proposta e desenvolver sua escrita. Estes textos motivadores são, entre outras coisa, subsídios para que o participante reflita, organize e selecione os argumentos que não fujam do tema e, portanto, constituem-se uma base/estrutura para a escrita da redação.

Diante do exposto, é possível notar que a disponibilidade de textos motivadores permite que o sujeito-aluno relacione-os, uma vez que eles mantêm uma profícua intertextualidade. Eles dizem, de outra maneira, sobre o que se pede na proposta de redação. A respeito dessa relação, Orlandi (2009) afirma que "não há discurso que não se relacione com outros" (p. 30). Tal como a autora (op.cit), compreendemos que os sentidos resultam de relações, na qual um discurso aponta para outros, pois não há começo absoluto nem ponto final para o discurso, ou seja, um dizer tem sempre relação com outros dizeres possíveis. São essas tramas de relações a que se abrem para os sentidos outros, isto é, esse jogo interdiscursivo torna possível a significação, a produção de sentidos.

Por outro lado, pode-se dizer que a relação entre os textos motivadores pode ser vista sob uma perspectiva de como o texto deve ser lido/interpretado pelo sujeito-leitor-escritor, ou seja, a leitura destes aponta para a escrita: o quê e o como escrever. Nota-se que há o funcionamento de ordem que interdita, também, outros dizeres, isto é, um saber discursivo já estabilizado. Em outras palavras, essa relação entre os textos motivadores pode ser vista como o fio condutor para que o sujeito-aluno atenda àquilo que está textualizado na formulação da proposta de redação. Percebe-se, entre outras coisas, um sujeito que precisa intervir sobre uma questão-problema e dar uma solução, colocando-se numa posição de responsável pelo que lê, pelo que escreve, pelo que propõe, sobretudo, pelo que pensa em face do que orienta o Estado, por meio da proposta de redação.

Posto isso, compreendemos que, pela incompletude da linguagem, todo texto tem relação com outros textos (ORLANDI, 2012); uma relação necessária com a exterioridade, na qual são estabelecidas as relações de sentido. Assim, o INEP, ao projetar textos que funcionam como base para a escrita da redação, produz diferentes gestos de interpretação, diferentes formas de linguagem, atravessadas por diferentes formações discursivas, diferentes condições de produção, que, juntas, significam de modo, igualmente, distintos.

Diante do que vimos afirmando em relação à normatização e/ou alinhamento produzida pela formulação da proposta de redação, trazemos, a seguir, a maneira como esta encontra-se textualizada na prova, enquanto um repetível que enquadra uma forma sujeito-aluno para a escrita. O comando da proposta diz:

\footnotetext{
${ }^{8}$ Os textos motivadores se referem à temática da proposta de redação. Eles se distribuem em textos verbais e nãoverbais. Normalmente, são disponibilizados de três a quatro textos motivadores.
} 
A partir da leitura dos textos motivadores seguintes e com base nos conhecimentos construídos ao longo de sua formação, redija um texto dissertativo-argumentativo em norma padrão da língua portuguesa [...], apresentando proposta de intervenção, que respeite os direitos humanos. Selecione, organize e relacione, de forma coerente e coesa, argumentos e fatos para defesa de seu ponto de vista (Proposta de Redação/Caderno Cinza, $2^{\circ}$ dia de prova, p. 01).

Gostaríamos de iniciar nossas reflexões com o posicionamento de Orlandi (2009) a respeito da Análise de Discurso. Para a autora, esta é uma teoria que ensina a pensar, que tira nossas certezas, fazendo com que o mundo fique mais amplo, menos sabido, mais desafiador. A nosso ver, esse é o ponto fulcral quando pensamos em um determinado objeto simbólicoanalítico, seja ele qual for. Esse processo de desnaturalização, de descortinar a opacidade, da qual afirma a autora, é algo engenhoso e demanda um ir e vir entre a teoria e análise, entretanto, nos possibilita dizer que a questão do sentido é sempre aberta, ela não se esgota. É dessa abertura, dessa fluidez da/na produção dos sentidos que trataremos no decorrer dessa escrita.

Primeiramente, há de se dizer que o conjunto de textos motivadores faz circular questões de ordem social, política e/ou cultural, o que configura um atravessamento de diferentes formações discursivas, ideológicas e imaginárias. Observa-se, desse modo, que o comando da proposta de redação marca uma relação com a exterioridade, ou seja, há um movimento na produção, na circulação e nos efeitos de sentidos que não fixam nos textos motivadores, mas que se significam no entremeio. Desse modo, compreendemos que a interpretação, sempre regida por condições de produção específicas é, nesse sentido, fundamental na relação entre a língua e sua exterioridade, uma vez que, enquanto gesto interpretativo, ela abre-se ao simbólico e possibilita a significação como constitutivas da linguagem.

Teoricamente, a ideologia é constitutiva do discurso; ela produz a opacidade, isto é, o efeito de evidência na língua (ORLANDI, 2012). Nesse sentido, considerando a relação línguadiscurso-ideologia, observa-se que há um imaginário de língua inscrito na proposta de redação, em que o candidato é individuado pelo Estado sobre a maneira de como deve proceder a escrita. Nota-se, pelo fio discursivo, que a formulação da proposição de redação se dá a partir de um dispositivo jurídico, que se assenta num respaldo legítimo do Estado e assegura a política de escrita proposta pelo INEP. Aqui estão imbricadas as relações de poder que, mais uma vez, silenciam/regulam outros modos de produção, outras formas de constituição no movimento dos sentidos.

Há que se dizer, ainda, que o repetível, inscrito na formulação da proposta de redação, nos faz observar que as políticas de língua são o lugar da regularidade (da unidade) e, neste caso, tem-se o enquadramento do participante do ENEM em uma formação imaginária, que ritualiza a maneira como o candidato deve proceder sua escrita. Ou seja, este é um efeito ideológico, ou melhor, é um gesto de apropriação de sentidos já circulantes, é um recorte político-simbólico textualizado em uma estrutura que se mantém: a modalidade dissertativo-argumentativa. Dito de outro modo, independente do assunto formulado na proposta há sempre a obrigatoriedade de o aluno ter que "solucionar" um problema de ordem social; é esse gesto que marca sua posiçãosujeito submissa às regularidades do Estado frente a um já-dito. O que queremos dizer com isso é que há uma voz institucional que projeta sujeitos para uma proposta de escrita, e ao instituir tal prática abre-se para o lugar de uma escrita higienizada', ao passo que regula o lugar da heterogeneidade.

Nessa linhagem, entendemos que o Estado, pelo efeito normatizador, projeta ideologicamente, uma posição-sujeito aluno capaz de intervir, pelos escritos, na redação, face a questões político-sociais. Essa responsabilidade, segundo Pêcheux (1990), é uma questão política, em que faz funcionar um imaginário que permeia as questões relacionadas ao ensino de língua e que resulta no processo de individuação da forma-sujeito pelo Estado (ORLANDI, 2012).

\footnotetext{
${ }_{9}$ Ver Barthes (1996), que trabalha com essas questões de imaginário de língua higienizada, depurada, clara e sem marcas indesejáveis.
} 
Compreendemos, dessa forma, que as condições de produção para a escrita da redação estão atravessadas por diferentes formações discursivas, que asseguram o que pode, o que deve e como deve ser dito, dada a situação de avaliação, isto é, há um cerceamento que diz respeito à maneira como o Estado (regulador) projeta, imaginariamente, posições-sujeitos para pensar conforme o que é, previamente, normatizado sobre escrita.

\section{As formações discursivas e imaginárias}

No discurso da proposta de redação observa-se que o sujeito-aluno está interdito pelas formações discursivas e imaginárias que permeiam a política de escrita da prova. Courtine (1984) afirma que os sentidos são regulados de acordo com determinada formação discursiva, que é o lugar de articulação entre língua e discurso e que regula o que pode e deve ser dito. Compreendese por isso que a formação discursiva que sustenta a política avaliativa do ENEM está relacionada às competências e habilidades do sujeito-aluno; produto de um saber autorizado, transmitido na/pela Escola que, ao escrever a redação, inscreve-se numa formação ideológica do Estado.

A formação imaginária que permeia o sujeito-aluno, no ENEM, se dá pela posição-sujeito no discurso e àquilo que o Estado projeta sobre si. Pêcheux (1995), ao pensar na relação das formações discursivas com a ideologia, propõe o conceito de formação imaginária como o mecanismo de funcionamento discursivo, que diz respeito às imagens resultantes das projeções dos sujeitos. Dessa forma, nota-se que há um imaginário de sujeito para a escrita da redação; projetado, imaginariamente, como "ideal" pela política de língua do Exame. Tem-se um enquadramento do sujeito-aluno em relação ao dizer institucional do Estado. Um dizer limitado, que regula o sujeito a posicionar-se conforme o que lhe é autorizado/permitido, via formulação da proposta de redação.

Discursivamente, sabe-se que o sujeito se significa pela escrita e por ela se constitui na relação com o social. Parafraseando Orlandi (2001), dizemos que o sujeito não se apropria da linguagem num movimento individual, mas na relação com o social, com o simbólico. Desse modo, na perspectiva discursiva, compreendemos que a proposta de redação, ao solicitar que os candidatos redijam um texto dissertativo-argumentativo com base na leitura dos textos motivadores e nos conhecimentos adquiridos ao longo da formação escolar, "selecionando, organizando, e relacionando, coerentemente, argumentos e fatos para a defesa de seu ponto de vista" (cf. Manual do Candidato), não toma o texto como produto do conhecimento do sujeitoaluno, mas como resultado de uma prática letrada, homogênea e linear. Nesse sentido, pressupõese que para escrever, precisa-se sempre de outros textos (motivadores/suportes), que serão (re)tomados pelo sujeito-escritor e não da leitura como um saber discursivo para a produção de texto.

A escrita se constitui carregada de historicidade, na qual o sujeito, em situação de avaliação, precisa estabelecer redes de sentidos para historicizá-la e produzir sentidos. Entretanto, o discurso do ENEM, atravessado ideologicamente pelo Estado, solicita, pelo comando da proposta de redação, que o sujeito-aluno "redija um texto do tipo dissertativo-argumentativo, na norma culta da Língua Portuguesa" (cf. Manual do Candidato). Há uma injunção a obedecer às ordens de um discurso pedagógico, inscrito numa posição idealista de como proceder à escrita do texto, o que produz como efeito a resistência no sujeito-aluno em não historicizar a prática de escrita e não relacioná-la à exterioridade. Em outras palavras, pode-se compreender que o sujeito tem de inserir seu dizer em um repetível para que o seu discurso seja interpretável e produza sentidos. Este é um efeito imaginário e resultado de uma prática ideológica.

Refletir sobre estas questões nos faz pensar que a prática de leitura, assim como a de escrita, implica a interpretação, entretanto, há coerções/regulações injungidas por mecanismos do Estado que silenciam e produzem um efeito de (re)produção nos sujeitos inscritos no Exame Nacional, isto é, a história de leitura e de escrita dessas posições-sujeito são desconsideradas. Isso nos remete ao que Orlandi (1996) dirá sobre as condições de interpretação que, por sua vez, não 
são iguais para todos, pois o conhecimento é distribuído de forma desigual. Em um contexto amplo, a afirmação da autora nos faz olhar para as bases da educação no país, em que a Escola é o espaço de produção do conhecimento, contudo, a desigualdade na distribuição desse conhecimento, em um contexto imediato, remete-nos aos mecanismos de regulação na prova do ENEM, que direciona a posição sujeito-aluno a pensar politicamente, como o Estado, administrando os saberes sobre o sujeito-aluno, de modo a traçar um perfil 'ideal'.

Ao refletirmos sobre a projeção imaginária de um "sujeito ideal" para a escrita da redação, observamos que há certa legitimação à linearidade na produção dessa escrita. Orlandi (1988, p. 113) diz que "a unidade do texto não é plana, nem simétrica, mas fugaz". A partir da autora (op.cit), compreendemos que a noção de incompletude é entendida como constitutiva na/para a produção (escrita) e seus efeitos de sentido, isto é, o incompleto na linguagem é o lugar do possível, é condição do movimento dos sentidos e dos sujeitos. Dito de outro modo, na perspectiva da Análise de Discurso a escrita é um trabalho discursivo em que o sujeito inscreve-se na língua para produzir sentidos; e quando falamos da relação sujeito-sentido, a questão do simbólico é sempre uma questão sempre aberta, que intervém. (ORLANDI, 2012). Daí dizermos que esse repetível que se mantém na proposta de redação é, pois, constitutivo, dessa relação sujeito/escrita.

De tudo o que discorremos a respeito da proposta de redação, inscrita e alicerçada em uma concepção de língua formal/culta, seguimos nossa análise, apresentando a maneira pela qual o discurso do Estado (Inep/Enem) solicita ao candidato a estrutura de texto para a escrita:

\begin{abstract}
O texto dissertativo-argumentativo é organizado na defesa de um ponto de vista sobre determinado assunto. É fundamentado com argumentos, para influenciar a opinião do leitor ou ouvinte, tentando convencê-lo de que a ideia defendida está correta [...] Seu objetivo é, em última análise, convencer ou tentar convencer o leitor, pela apresentação de razões e pela evidência de provas, à luz de um raciocínio coerente e consistente. (In: Guia do Participante/ENEM 2015, p.15).
\end{abstract}

O recorte diz, entre outras coisas, que o objetivo do aluno é convencer o leitor pela escrita. Há uma injunção de o candidato ter que escrever para convencer e, diríamos, vencer, pela escrita, o idealismo de ser coerente com a proposição do que se solicita no enunciado da prova de redação. Nota-se distintas formas de atravessamento de leituras, de conhecimentos para a escrita do texto dissertativo. Dessa forma, o recorte produz efeitos de sentido, em que o sujeito-escritor deverá apresentar e defender uma posição a respeito de determinado tema.

Denomina-se texto argumentativo porque se trata de defender uma tese (ideia/opinião) estruturada em proposição, argumentação e conclusão (cf. Manual do Candidato, ENEM 2015). Isso nos leva a compreender que o processo de leitura e de escrita no ENEM se dá para um sujeito que tem domínio da modalidade textual do tipo dissertativo-argumentativo. Essa tipologia exige do participante a capacidade de construir argumentos, pensar, refletir e intervir diante de problemáticas sociais, sobretudo, propondo soluções.

A nosso ver, a restrição à modalidade dissertativa, no ENEM, traz graves consequências para o ensino da escrita, principalmente, no ensino médio, uma vez que o aluno, com a finalidade de alcançar uma boa nota na prova de redação do ENEM, passa a 'treinar' apenas o texto dissertativo (LUNA, 2009). Isso contribui para a padronização e engessamento de 'textos que dão certo', o que possibilita a "preparação"10 dos alunos para a prova, a fim de obterem uma boa nota na redação. Cria-se um imaginário de tipologia textual (dissertativo-argumentativo), que passa a servir como "fórmula", contribuindo para o efeito de uma projeção imaginária idealizada de sujeito e de texto.

Nessa linhagem, recortando nossa questão para as considerações finais, dizemos que o imaginário sobre o ensino de produção de textos, calcado em uma "fórmula" é, ainda hoje, muito

${ }^{10}$ Esta é uma questão que demanda uma maior reflexão, entretanto a trazemos aqui, uma vez que ela é efeito dessa prática de produção escrita exigida o Exame Nacional. 
praticado nas escolas e o Exame Nacional, a partir da solicitação do comando da proposta de redação, contribui com essa tese ao "alinhar" o aluno para escrever um texto na modalidade dissertativo-argumentativa, como condição para que sua redação seja aceita, conforme a política de língua do Exame. Essas e outras questões são, muitas vezes, naturalizadas pelo próprio discurso do Estado que, ao instituir tal modelo, corrobora para o enquadramento de candidatos a ocuparem determinadas vagas no ensino superior: uma política meritocrática que aponta para a exclusão.

Ao propormos refletir sobre a política de avaliação do ENEM, particularmente, as questões que tocam diretamente a relação sujeito-escrita, procuramos não filtrar resultados, mas levantar questões e refletir sobre elas, desnaturalizando discursos previamente estabilizados. Isso porque esse é, também, o ponto nodal a qual a teoria da Análise de Discurso se propõe a fazer. Dessa maneira, recortamos nossas reflexões para as considerações finais, sabendo que inúmeras outras questões são pertinentes e podiam acrescentar-se as que aqui foram articuladas, contudo, o ponto final se faz necessário.

\section{CONSIDERAÇÕES FINAIS}

À guisa de um fechamento e retomando nossa proposta inicial, que foi a de pensar, a partir da política de avaliação do Exame Nacional, as normas de escrita instituídas na/pela prova, podemos dizer que há, inscrito na formulação da proposta de redação, o imaginário de um sujeito-aluno "ideal", projetado por uma política de Estado que institui e regula o Exame. Nossas análises mostraram que esse imaginário de candidato é resultado de uma política normalizadora, homogênea e restrita àquilo a qual se propõe enquanto uma avaliação em larga escala, como é o caso da prova em questão.

Desse modo, em um sentido amplo de leitura, observa-se que o ENEM busca "captar" o modo particular de interpretação do candidato. Assim, pode-se dizer que a escrita da redação está inscrita em um imaginário de registro formal de linguagem (norma culta da língua), cabendo ao candidato adequar seu uso de linguagem ao registro discursivo inscrito na proposta de redação e nas competências avaliativas. O participante do ENEM, em sua posição sujeito-escritor, circula por um imaginário de escrita legitimado pelo Estado e solicitado na proposição do MEC/INEP e inscrito num lugar de "regularidade na língua". Dessa forma, ao falar da projeção imaginária "ideal" do aluno no discurso do ENEM, falamos da imagem que o Estado projeta desse sujeito em relação ao conhecimento de língua, de escrita e, sobretudo, de sua capacidade discursivoargumentativa.

A análise da formulação da proposta de redação e o enquadramento de uma forma-sujeito projetada no/pelo discurso do INEP nos remete a Milner (1987, p. 39) que diz: "na língua há sempre a impossível; o impossível de dizer tudo". Segundo o autor, o tudo na língua se materializa pela incompletude e pelo movimento dos sentidos. Ao afirmar que "o tudo não pode ser dito" (MILNER, op.cit), entendemos que toda língua é afetada por uma divisão, um impossível, inscrita em sua ordem. Assim, há de se pensar no modo heterogêneo de constituição da escrita pela relação sujeito/linguagem.

Dessa maneira, compreendemos, ao final deste trabalho, que a escrita instituída pelo porta-voz INEP faz ler o discurso pedagógico institucionalizado, que projeta a regularidade e a homogeneidade da língua; ou seja, é a lei que institui um modo de pensar a escrita no processo seletivo. No entanto, do ponto de vista discursivo, não há como conceber a homogeneidade do texto, nem mesmo o imaginário de escrita e/ou de sujeito. Pelo viés discursivo consideramos as margens, as falhas, o heterogêneo, os deslizes, os efeitos de sentidos, sobretudo, a incompletude, enquanto modos de observarmos a heterogeneidade na escrita.

Por fim, pode-se dizer que avaliar as competências e as habilidades dos alunos por meio da redação, desloca-se para sentidos outros, cuja finalidade fundamenta-se no 'diagnóstico' de "competências" ou "incompetências" para a escrita. Nesse sentido, o Exame visa, entre outras 
coisas, obter um extrato (nota) do nível de aprendizado dos alunos, visto que há uma política de escrita no ENEM que aponta para o ingresso ao ensino superior. Essa questão se marca pelo fato de que escrever para a universidade passa por determinadas competências avaliativas, cujo efeito é de um sujeito inscrito numa política meritocrática que nomeia certo modo de escrever.

Tudo isso nos faz pensar no gesto de intepretação que permeia a formulação da proposta de redação, na política de escrita do ENEM e um olhar outro para a sala de aula. Urge, portanto, a necessidade de ir além do imediatismo dos dados numéricos/estatísticos do INEP que dizem sobre o nível do ensino no Brasil, e pensar nas condições de produção de leitura e escrita, sobretudo na posição-sujeito-aluno, inscrito no lugar real do ensino de escrita na Escola.

\section{REFERÊNCIAS BIBLIOGRÁFICAS}

ALVES, Paulo Afonso da Cunha. ENEM como política pública de avaliação. 102 f. Dissertação (Mestrado em Políticas Públicas e Formação Humana) - Faculdade de Educação, UERJ, Rio de Janeiro, 2009.

AUROUX, Sylvain. A Revolução tecnológica da gramatização. Tradução de Eni Orlandi. Campinas, SP: Editora da UNICAMP, 1992.

BARTHES, Roland. O prazer do texto. Trad. J. Guinsburg. 4. ed. São Paulo: Perspectiva 1996.

BRASIL. Instituto Nacional de Estudos e Pesquisas Educacionais Anísio Teixeira. A redação no ENEM 2015: guia do participante. Brasília: INEP, MEC, 2013. Disponível em: http://download.inep.gov.br/educacao basica/enem/guia participante/2013/guia de redacao enem 2 013.pdf. Acesso em 24 nov. 2015.

CORRÊA, Manoel Luiz Gonçalves. O modo heterogêneo de constituição da escrita. Tese (Doutorado em Linguística) - IEL, UNICAMP, Campinas, 1997.

COURTINE, Jean Jacques. Définitions d'orientations théoriques et méthodologiques en analyse de discours in philosophiques. v. IX, n. 2. Paris, 1984.

LUNA, Ewerton Ávila dos Anjos. Avaliação da produção escrita no ENEM: como se faz e o que pensam os avaliadores. 156 f. Dissertação (Mestrado em Educação) - UFPE, Recife, 2009.

MILNER, Jean Claude. O amor da língua. Porto Alegre: Artes Médicas, 1987.

NUNES, José Horta. Formação do leitor brasileiro: imaginário de leitura no Brasil Colonial. Campinas, SP. Editora da UNICAMP, 1994.

ORLANDI, Eni. Puccinelli. Língua brasileira e outras histórias: discurso sobre a língua e ensino no Brasil. Campinas: Editora RG, 2009.

. Breve retrospecto sobre o ensino da Língua. In: Revista Relatos, $n^{\circ}$ 03. Publicado pelo Projeto História das Ideias Linguísticas, IEL-UNICAMP, 1996.

Interpretação: Autoria, leitura e efeitos do trabalho simbólico. 6. ed. Campinas, SP: Pontes Editores, 2012.

. Discurso e leitura. Campinas, SP. Editora Cortez, 1988. 
. Discurso e texto: Formulação e Circulação de Sentidos. Campinas: Pontes, 2001.

Língua e conhecimento linguístico: Para uma história das ideias no Brasil. São

Paulo: Cortez, 2002.

PÊCHEUX, Michel. Os fundamentos teóricos da Análise Automática do Discurso de Michel Pêcheux (1969). In: Por uma análise automática do discurso: uma introdução à obra de Michel Pêcheux. Gadet, F. \& Hack, T. Tradução: B. Mariani et al. Campinas, São Paulo: Editora da Unicamp, 2010.

. Semântica e discurso: uma crítica à afirmação do óbvio. Trad. Eni P. Orlandi. 2. ed. Campinas, UNICAMP, 1995.

Delimitações, inversões, deslocamentos. Trad. José Horta Nunes. In: Cadernos de Estudos Linguísticos, Campinas (19): 7-24, jul.dez, 1990.

SILVA, Mariza Vieira da. História da Alfabetização no Brasil: a constituição de sentidos e do sujeito da escolarização. Tese (Doutorado em Linguística) - IEL, UNICAMP, Campinas, 1998.

SOBRINHO, José Dias. Avaliação: políticas educacionais e reformas da educação superior. São Paulo: Cortez, 2003.

Recebido em 27/01/2017

Aceito em 11/05/2017

Publicado em 11/05/2017 